\title{
Rapid Decolorization of Cobalamin
}

\author{
Falah H. Hussein and Ahmed F. Halbus \\ Chemistry Department, College of Science, Babylon University, P.O. Box 51002, Hilla, Iraq \\ Correspondence should be addressed to Falah H. Hussein, abohasan_hilla@yahoo.com
}

Received 14 May 2012; Revised 24 June 2012; Accepted 12 July 2012

Academic Editor: Huogen Yu

Copyright ( 2012 F. H. Hussein and A. F. Halbus. This is an open access article distributed under the Creative Commons Attribution License, which permits unrestricted use, distribution, and reproduction in any medium, provided the original work is properly cited.

\begin{abstract}
The photocatalytic decolorization of cobalamin was carried out in aqueous solution of different types of catalysts including $\mathrm{ZnO}$, $\mathrm{TiO}_{2}$ (Degussa P25), $\mathrm{TiO}_{2}$ (Hombikat UV100), $\mathrm{TiO}_{2}$ (Millennium PC105), and $\mathrm{TiO}_{2}$ (Koronose 2073) by using UVA source of irradiation. The effect of various parameters such as photocatalyst amount, cobalamin concentration, type of catalyst, $\mathrm{pH}$ of aqueous solution, light intensity, addition of $\mathrm{H}_{2} \mathrm{O}_{2}$, flow rate of $\mathrm{O}_{2}$, type of current gas, and temperature on photocatalytic oxidation was investigated. The results indicated that the photocatalytic decolorization of cobalamin was well described by pseudo-firstorder kinetics according to the Langmuir-Hinshelwood model. The effect of temperature on the efficiency of photodecolorization of cobalamin was also studied in the range $278-298 \mathrm{~K}$. The activation energy was calculated according to Arrhenius plot and was found equal to $28 \pm 1 \mathrm{~kJ} \cdot \mathrm{mol}^{-1}$ for $\mathrm{ZnO}$ and $22 \pm 1 \mathrm{~kJ} \cdot \mathrm{mol}^{-1}$ for $\mathrm{TiO}_{2}$ (Degussa P25). The results of the total organic carbon (TOC) analysis indicate that the rate of decolorization of dye was faster than the total mineralization. Decolorization and mineralization of cobalamin in the absence of light and/or catalyst were performed to demonstrate that the presence of light and catalyst is essential for the decolorization of this cobalamin. The results show that the activity of different types of catalysts used in this study was of the sequence: $\mathrm{ZnO}>\mathrm{TiO}_{2}$ (Degussa P25) $>\mathrm{TiO}_{2}\left(\right.$ Hombikat UV100) $>\mathrm{TiO}_{2}\left(\right.$ Millennium PC105) $>\mathrm{TiO}_{2}($ Koronose 2073).
\end{abstract}

\section{Introduction}

Frank and Bard in 1977 stated that it was possible to use $\mathrm{TiO}_{2}$ to degrade the organic compound in water [1]. Photodegradation of organic and inorganic pollutants on different types of semiconductors has been studied by several researchers. Dyes have become one of the important industry pollutants that lead to environmental contamination. To find a general process for treatmentof the color of dye used in dyeing processes is very difficult due to the complexity and variety of these types of industrial wastewater [2]. In recent years, the interest has been focused on the use of semiconductor in photocatalytic decolorization of different types of wastewater where the band gap for zinc oxide is $(\sim 3.2 \mathrm{e.V})$. In addition, their photocatalytic activities are shown only under UV irradiations. However, the presence of colored compounds on the surface of the semiconductor can absorb a radiation in the visible range and then is excited by a process called photosensitization process. The hydroxyl group radical $(\bullet \mathrm{OH})$, which is formed by the photocatalytic process, from the photosensitization processes, will oxidize all the organic compounds to $\mathrm{CO}_{2}$ and $\mathrm{H}_{2} \mathrm{O}$ (mineralization) [3]. Several processes were used for the treatment of pollutants such as biodegradation, catalytic oxidation, chemical treatment (chlorine, ozone, hydrogen peroxide), and degradation by high-energy ultraviolet light $[4,5]$. One of the active methods to treat the colored wastewater is advance oxidation process (AOP) including photocatalysis degradation systems which use a semiconductor $\left(\mathrm{TiO}_{2}\right.$ or $\left.\mathrm{ZnO}\right)$ and UV light [6]. Titanium dioxide is one of the best materials which have good ability to destroy the organic materials and active species to un-harmful material by using light/semiconductor system [7].

The photocatalytic activity of semiconductors can be enhanced by using different techniques [8-15]. Zhou et al. showed that doping of titanium dioxide with gold ( $\mathrm{Au}-$ $\mathrm{TiO}_{2}$ ) nanocomposites gives higher activity in visible-light for degradation of Rhodamine-B $(\mathrm{RhB})$ in water [8].

Wang et al. observed that the calcination temperature of $\mathrm{TiO}_{2}(\mathrm{P} 25)$ at $500^{\circ} \mathrm{C}$ caused to double the activity of $\mathrm{TiO}_{2}$ 


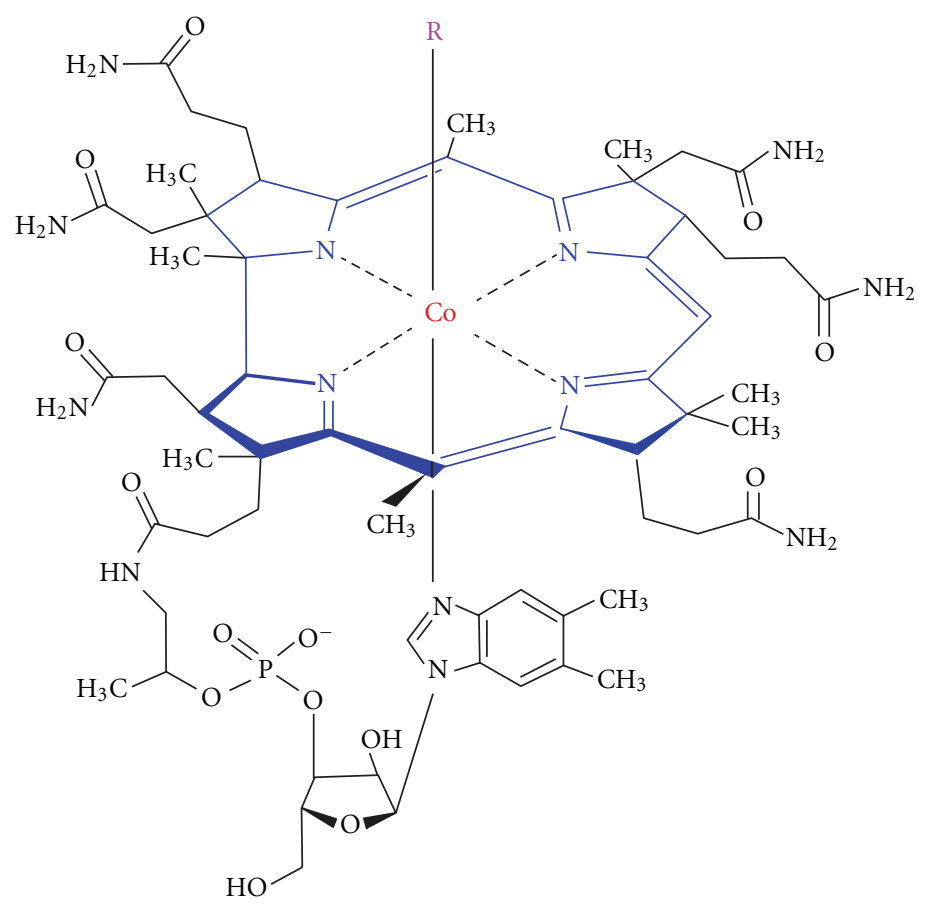

Figure 1: Structure of cobalamin.

(P25) for photocatalytic degradation of methyl orange (MO) [9]. Wu et al. studied a comparison between the photocatalytic activity (PC) and photoelectrocatalytic activity (PEC) of methylene blue (MB) [11]. They have noticed that the photoelectrocatalytic activity is more efficient than photocatalytic activity. There are different studies using doped metal on $\mathrm{TiO}_{2}$ surface to enhance the activity of catalyst or to reduce the band gab of semiconductor [10-15].

Heterogeneous photocatalysis is a method used for the degradation of various types of organic pollutants in water and wastewater [16]. Different types of semiconductors such as $\mathrm{TiO}_{2}, \mathrm{ZnO}, \mathrm{CdS}$, and $\mathrm{ZnS}$ and irradiation source of UV or visible lights can be used in photocatalysis systems. In the process of irradiation of the semiconductor with energy equal or greater than the band gap, the electrons in valence band are promoted to the conduction band leaving a hole behind. The holes at the valence bond have an oxidation potential of $+2.6 \mathrm{~V}$ with normal hydrogen electrode (NHE) at $\mathrm{pH}=7$. This energy is enough to oxidize water molecule or hydroxide and produce hydroxyl radicals or oxidize wastewater containing various types of dyes $[17,18]$. The photosensitization process is defined in summary term as photocatalytic decolorization of dyes, and this process also follows the mechanism of free radical, where the adsorbed dyes molecules on the semiconductor surface have ability to absorb a radiation in with short wavelength or in the visible region [19-21]. Therefore the excited colored dye either in singlet or triplet states shall inject an electron to the conduction band for the chosen semiconductor [22].

Porphyrins are aromatic compounds that have a highly conjugated system and composed of four smaller 5-membered heterocycles. They are called pyrroles that contain one nitrogen and four carbon atoms. In porphyrins, one carbon is typically referred to as the mesocarbon, serving the connection of each of the four pyrrole rings [23]. Porphyrins are intensely colored cyclic molecules which occur in nature as in green leaves and red blood cells. Porphyrins are characterized by the presence of four modified pyrrole subunits interconnected at their $\alpha$ carbon atoms with methane bridges $(=\mathrm{CH}-)$ [24].

Cobalamin, also known as vitamin $\mathrm{B}_{12}$, is a complex organometallic compound which is formed by the situated cobalt atom in a corrin ring [25]. The structure of cobalamin is shown in Figure 1.

The central metal ion in the cobalamin is cobalt. While four of the six coordination sites are provided by the corrin ring, the fifth is provided by a dimethylbenzimidazole group. The sixth coordination site, the center of reactivity, is variable as it can be a cyano group $(-\mathrm{CN})$, a hydroxyl group $(-\mathrm{OH})$, a methyl group $\left(-\mathrm{CH}_{3}\right)$, or a $5^{\prime}$-deoxyadenosyl group (here the $\mathrm{C}^{\prime}$ atom of the deoxyribose forms the covalent bond with Co), respectively, to yield the four cobalamin forms mentioned above [26].

Cobalamin is soluble in water and has the molecular formula $\mathrm{C}_{63} \mathrm{H}_{88} \mathrm{CoN}_{14} \mathrm{O}_{14} \mathrm{P}$, mole mass $1355.37 \mathrm{~g} / \mathrm{mol}$. The systematic (IUPAC) name is $\alpha$-(5,6-dimethylbenzimidazolyl) cobamidcyanide. It can be produced industrially only through bacterial fermentation-synthesis. Cobalamin consists of a class of chemically-related compounds (vitamers) such as cyanocobalamin, methylcobalamin, adenosylcobalamin, and hydroxocobalamin. The various forms of isomers of $\mathrm{B}_{12}$ are all deeply red colored, due to the color of the cobalt-corrin complex [27]. Photolysis of cobalamin in aqueous solution produced hydroxocobalamin. The kinetics 
of photolysis was found to follow zero-ordar kinetics at different $\mathrm{pH}$ and the rate was catalysed by both hydrogen and hydroxyl ions [28].

The idea of this work was derived from the announcement of NineSigma company in October 2010 about decolorization of porphyrin species proposal number 66645 (rapid decolorization of porphyrin species). The company aimed to decolorize porphyrin species to prevent staining or noticeable transfer to cloth and other absorbant surfaces. The aim of this study was to investigate the photocatalyst decolorization of cobalamin using different types of catalyst, namely, $\mathrm{ZnO}, \mathrm{TiO}_{2}$ (Degussa P25), $\mathrm{TiO}_{2}$ (Hombikat UV100), $\mathrm{TiO}_{2}$ (Millennium PC105), and $\mathrm{TiO}_{2}$ (Koronose 2073). The effect of different parameters was studied to estimate the best condition for decolorization of cobalamin.

\section{Experimental}

Photocatalytic reactions were carried out in a batch photoreactor with the radiation source type Philips (CLEO), Poland, mercury lamps containing 6 lamps with $15 \mathrm{~W}$ for each. Aqueous suspensions of zinc oxide $(\mathrm{ZnO})$ or titanium dioxide $\left(\mathrm{TiO}_{2}\right)$ containing cobalamin in beaker, under magnetic stirring, were irradiated in light of wavelength $365 \mathrm{~nm}$ with an irradiation intensity of $\left(0.5-3 \mathrm{~mW} \cdot \mathrm{cm}^{-2}\right)$. In all experiments, the required amount of the catalyst was suspended in $100 \mathrm{~cm}^{3}$ of aqueous solution of cobalamin. After illumination, $2 \mathrm{~mL}$ was taken from the reaction suspension, centrifuged at 4,000 rpm for 15 minutes in an $800 \mathrm{~B}$ centrifuge, and filtered to remove the particles. The second centrifuge was found necessary to remove fine particle of the zinc oxide or titanium dioxide $\left(\mathrm{TiO}_{2}\right)$. After the second centrifuge, the absorbance of the cobalamin was measured at $361 \mathrm{~nm}$ and $550 \mathrm{~nm}$, respectively, using Cary 100Bio UV-visible spectrophotometer shimadzu. The measurements at the two wavelength produced equivalent results, when compared with the prepared calibration curves.

The photocatalytic decolorization rate of cobalamin is described by pseudo-first-order kinetics according to the Langmuir-Hinshelwood model, so the rate of photocatalytic decolorization of cobalamin could be expressed by the following:

$$
C_{t}=C_{o} e^{-k t}
$$

where $C_{t}$ represents cobalamin concentration at time $t$ of irradiation, $C_{o}$ is the initial concentration, $k$ is the apparent reaction rate constant of the pseudo-first-order kinetics, and $t$ is irradiation exposure time [3]:

$$
\begin{aligned}
\frac{C_{t}}{C_{o}} & =e^{-k t}, \\
\ln \frac{C_{t}}{C_{o}} & =-k t, \\
\text { or } \quad \ln \frac{C_{o}}{C_{t}} & =k t .
\end{aligned}
$$

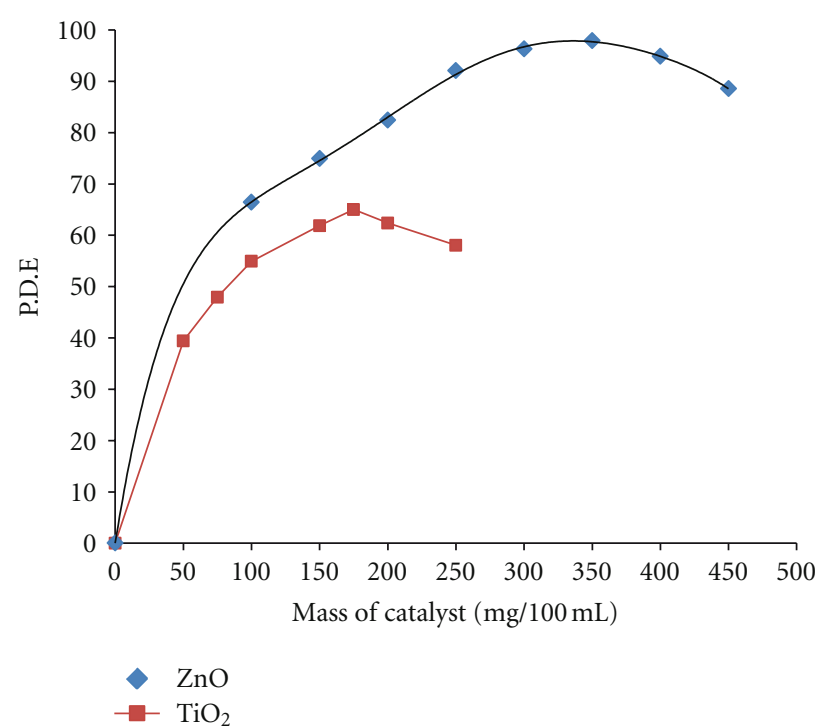

FIGURE 2: Effect of the masses of catalyst on photodecolorization efficiency of cobalamin.

The photodecolorization efficiency (P.D.E) of cobalamin was calculated from a mathematical equation adapted from measurements of decolorization used before [29]:

$$
\text { P.D.E }=\frac{C_{o}-C_{t}}{C_{o}} \times 100,
$$

where $C_{o}$ is the initial concentration of cobalamin, $C_{t}$ represents cobalamin concentration at time $t$ of irradiation.

\section{Results and Discussion}

3.1. Effect of Mass Catalyst of $\mathrm{ZnO}$ or $\mathrm{TiO}_{2}$. The photodegradation efficiency of cobalamin increased with the increase of the amount of catalyst up to an optimum value and then decreased slightly with the increase of the amount of catalyst as shown in Figure 2. One possible explanation for such behavior is that it is believed that an increase in the number of catalyst will increase the number of photons absorbed and the number of cobalamin molecules adsorbed. Therefore, the photodegradation rate can be expected to be enhanced on increasing the amount of catalyst due to the increase in total surface area available for contaminant adsorption. However, a further increase of the catalyst concentration may cause light-screening effects [30]. These screening effects reduce the specific activity of the catalyst [31].

3.2. Effect of Initial Dye Concentration of $\mathrm{ZnO}$ or $\mathrm{TiO}_{2}$. The effect of the initial concentration of cobalamin on the photocatalytic decolorization was studied by varying the initial concentration over a wide range. At a fixed $\mathrm{pH}$ and amount of catalyst, photocatalytic experiments were carried out at different initial concentrations of cobalamin. The results in Figure 3 show that the rate constant of photodecolorization decreased with increasing the initial cobalamin concentration [32]. This behavior can have the explanation that 


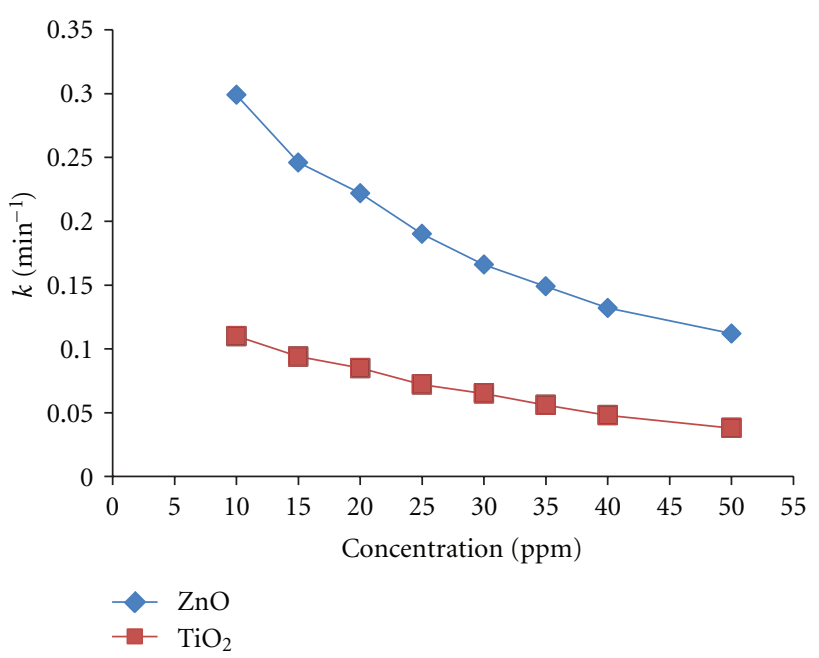

FIGURE 3: Effect of initial dye concentration on rate constant.

the initial concentration of the cobalamin increases because the path length of the photons log in the solution decreases and in low concentration the reverse effect is observed, thereby increasing the number of photon absorption by the catalyst in lower concentration [33].

3.3. Effect of $p H$. The results in Figure 4 show that the photodecolorization efficiency increased with the increase of the $\mathrm{pH}$ value of solution to $\mathrm{pH} 9.01$ for $\mathrm{ZnO}$ and $\mathrm{pH} 6.59$ for $\mathrm{TiO}_{2}$ (Degussa P25) and then decreases. The production of hydroxyl radicals is also a function of $\mathrm{pH}$. Therefore, $\mathrm{pH}$ is an important parameter in photocatalytic reactions. The photodecolorization of cobalamin was studied at different $\mathrm{pH}$. In all the experiments, $\mathrm{pH}$ was adjusted by using appropriate amounts of base $(\mathrm{NaOH})$ or acid $(\mathrm{HCl})$ solutions [34-37]. The zero point charge (ZPC) is equal to 9.01 for $\mathrm{ZnO}$ and 6.59 for $\mathrm{TiO}_{2}$ (Degussa P25) and the semiconductor surface will remain positively charged in acidic medium and negatively charged in alkaline medium, because the ionization state of the surface of semiconductor is according to the following reactions:

$$
\begin{gathered}
\mathrm{ZnOH}+\mathrm{H}^{+} \longrightarrow \mathrm{ZnOH}_{2}{ }^{+} \\
\mathrm{ZnOH}+\mathrm{OH}^{-} \longrightarrow \mathrm{ZnO}^{-}+\mathrm{H}_{2} \mathrm{O} \\
\mathrm{TiOH}+\mathrm{H}^{+} \longrightarrow \mathrm{TiOH}_{2}^{+} \\
\mathrm{TiOH}+\mathrm{OH}^{-} \longrightarrow \mathrm{TiO}^{-}+\mathrm{H}_{2} \mathrm{O} .
\end{gathered}
$$

This behavior can be explained when the $\mathrm{pH}$ value of the solution is increased up to a maximum value and then decreased, this is because in alkaline medium the surface area of photocatalyst possesses much negative charge [38-41].

3.4. Effect of Temperature. The effect of temperature on photocatalytic decolorization of cobalamin in water solution was investigated in the range of $278.15-298.15 \mathrm{~K}$. The results in Figure 5 show that the degradation efficiency of cobalamin

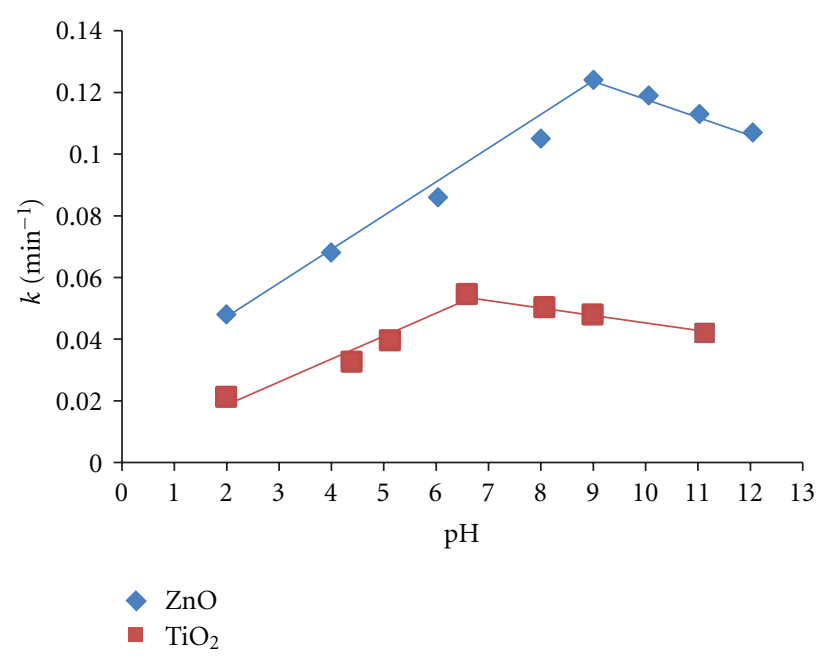

Figure 4: Effect of initial pH of solution on rate constant.

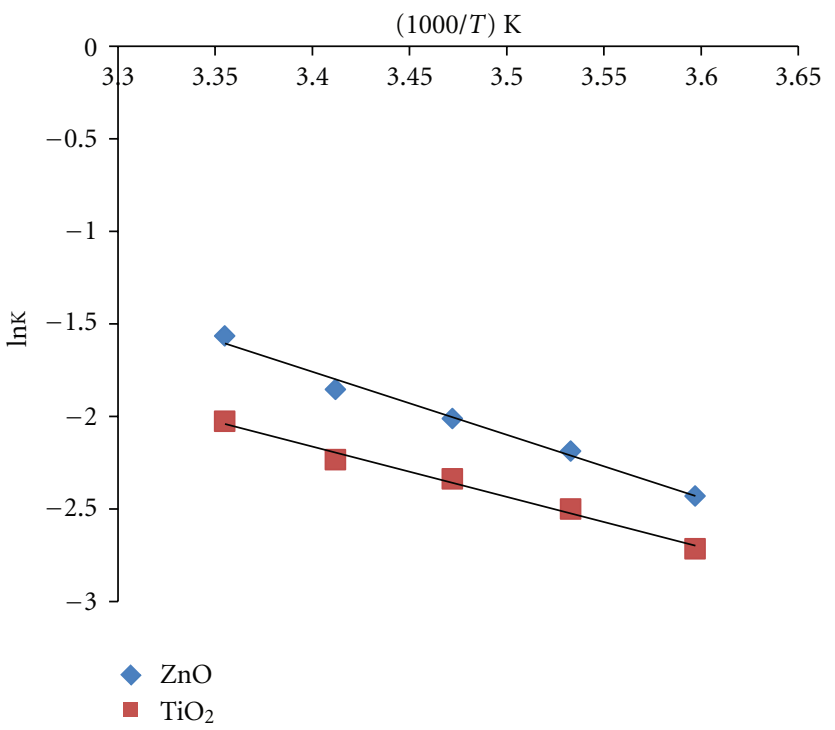

FIgURE 5: Arrhenius plot.

gradually increased with increase in the temperature. The increase in temperature would lead to generating the free radicals [42]. Therefore, the rise in temperature helped the reaction to compete more efficiently than electron-hole recombination [43]. The increasing of temperature may increase the oxidation rate of cobalamin and also reduce the adsorption capacities associated with cobalamin and dissolved oxygen [44]. Generally the rise in temperature can affect the amount of adsorption [45]. Arrhenius plot shows that the activation energy for photocatalytic decolorization of cobalamin is equal to $28 \pm 1 \mathrm{~kJ} \mathrm{~mol}^{-1}$ for $\mathrm{ZnO}$ and $22 \pm 1 \mathrm{~kJ} \mathrm{~mol}^{-1}$ for $\mathrm{TiO}_{2}$ [46].

3.5. Effect of Light Intensity. The effect of light intensity on the decolorization efficiency for cobalamin was examined at constant initial cobalamin concentration (40 ppm). It is 


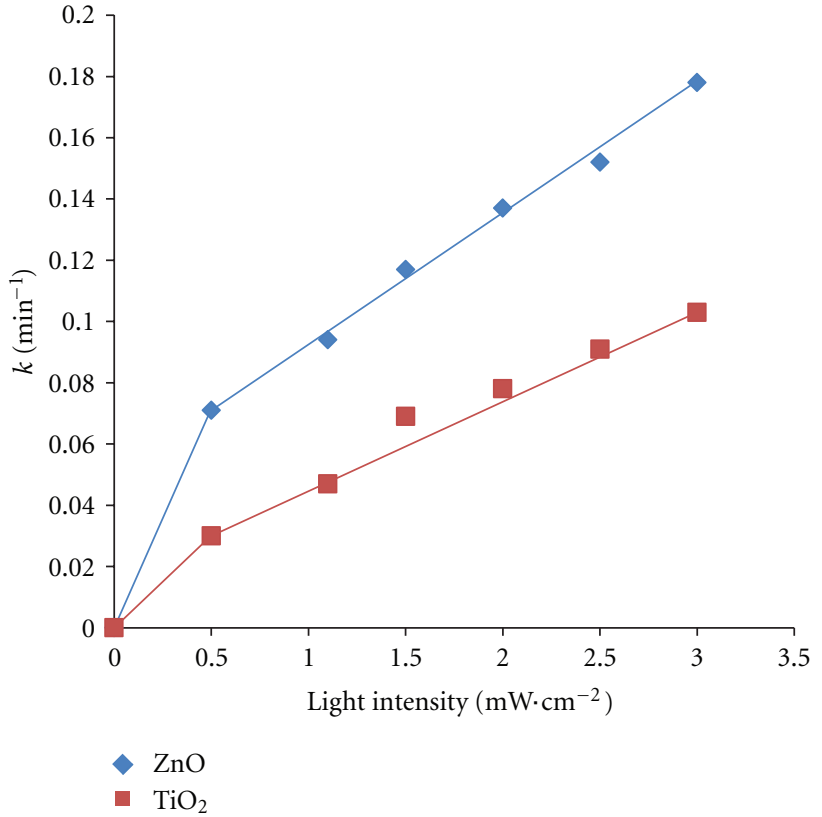

FIGURE 6: Effect of initial light intensity on the rate constant.

found that the percentage of decolorization and photodecolorization for cobalamin increases with increasing the light intensity as shown in Figure 6. The light intensity was studied in the range $(0.5-3) \mathrm{mW} \cdot \mathrm{cm}^{-2}$ by changing the high and lowering the lamps. From these results it is found that the decolorization rate for cobalamin increased with increase in the light intensity [47]. This behavior can be explained that the UV irradiation production the photons required for the electron transfer from the valence band to the conduction band in the catalyst. photocatalyst and the energy of a photon is related to its wavelength and the overall energy input to a photocatalytic process is dependent on light intensity. The rate of decolorization for cobalamin increases when more radiations fall on the catalyst surface and hence more ${ }^{\bullet} \mathrm{OH}$ radicals are generated on catalyst surface $[48,49]$.

3.6. Effect of Current Gas. The results in Figures 7 and 8 show that the photodecolorization efficiency for cobalamin increased with the presence of the oxygen gas $\left(\mathrm{O}_{2}\right)$ but decreased or was extremely slow in the presence of the nitrogen gas $\left(\mathrm{N}_{2}\right)$. This behavior can be explained that in the presence of nitrogen gas $\left(\mathrm{N}_{2}\right)$ and $\mathrm{TiO}_{2}$ (Degussa P25) will production grey-blue in color may be attributed to the sharing of lattice oxygen from the surface. The results indicated that the presence of oxygen is necessary $[50,51]$. The presence of oxygen in the solution plays an important role in the photocatalytic decolorization of cobalamin. This behavior can be explained that the oxygen molecule acts as an electron acceptor and minimizes the chance of electron-hole pair recombination [52].

3.7. Effect of Addition of $\mathrm{H}_{2} \mathrm{O}_{2}$. Hydrogen peroxide $\left(\mathrm{H}_{2} \mathrm{O}_{2}\right)$ plays an important role in the production of hydroxyl radicals. The effect of addition of hydrogen peroxide $\mathrm{H}_{2} \mathrm{O}_{2}$

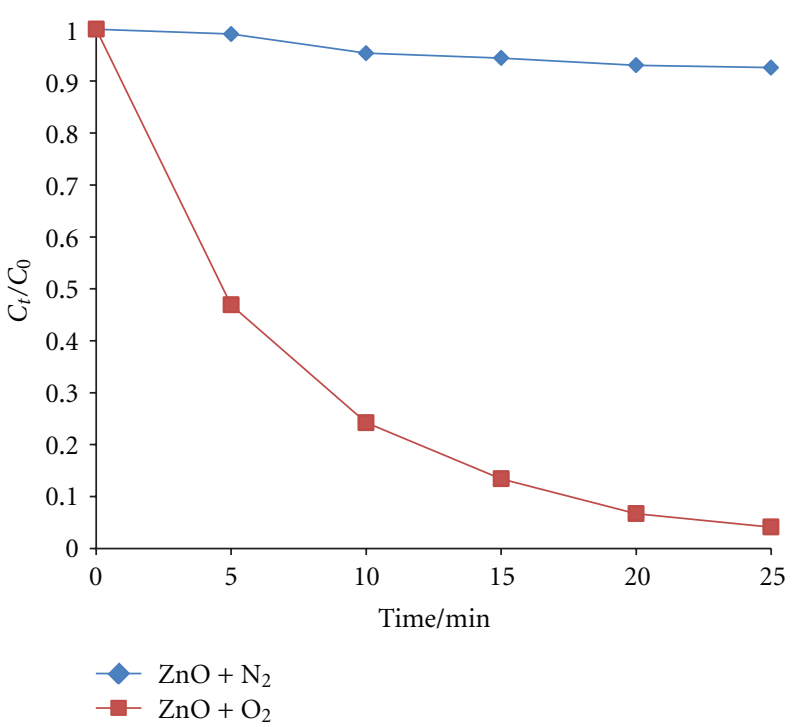

FIGURE 7: Effect of type of gas on photodecolorization of cobalamin by $\mathrm{ZnO}$.

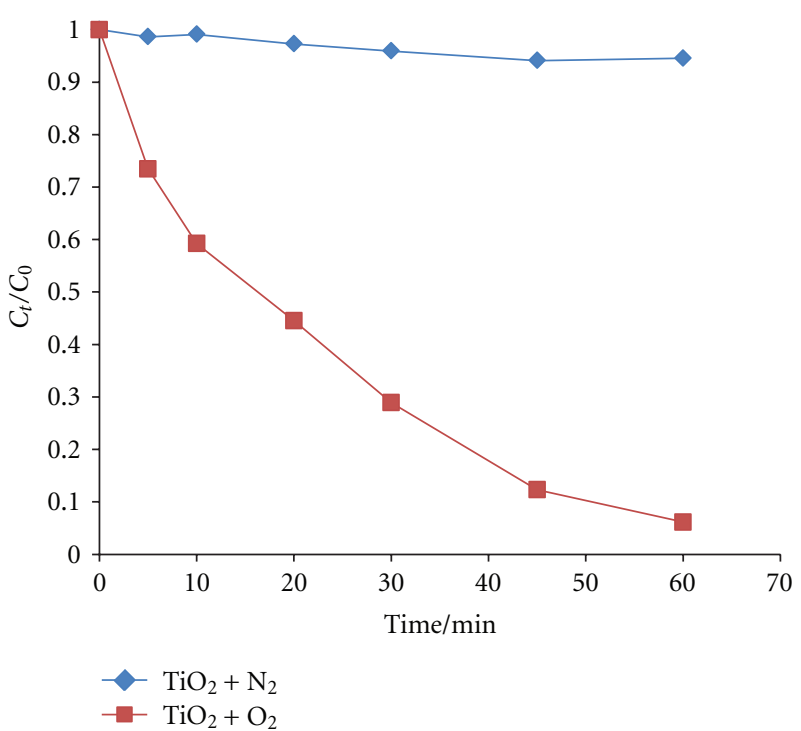

FIGURE 8: Effect of type of gas on photodecolorization of cobalamin by $\mathrm{TiO}_{2}$.

on the decolorization rate was studied for photocatalytic decolorization of the cobalamin. The results in Figure 9 show that the decolorization rate increase in with increases concentration of hydrogen peroxide $\mathrm{H}_{2} \mathrm{O}_{2}$ from 0.1 to $1.5 \mathrm{mmol} / \mathrm{L}$, becomes maximum at $1.5 \mathrm{mmol} / \mathrm{L}$ and then - $\mathrm{OH}$ starts decreasing from 1.5 to $4.0 \mathrm{mmol} / \mathrm{L}$ with increase in the concentration of hydrogen peroxide $\mathrm{H}_{2} \mathrm{O}_{2}$ [53].

This behavior is due to increasing the concentration of hydroxyl radical since it inhibits the hole-electron recombination according to the following equations:

$$
\begin{gathered}
\mathrm{H}_{2} \mathrm{O}_{2}+e_{\mathrm{cb}}^{-} \longrightarrow \cdot \mathrm{OH}+\mathrm{OH} \\
\mathrm{H}_{2} \mathrm{O}_{2}+{ }^{\bullet} \mathrm{O}_{2} \longrightarrow \cdot \mathrm{OH}+\mathrm{OH}+\mathrm{O}_{2} .
\end{gathered}
$$




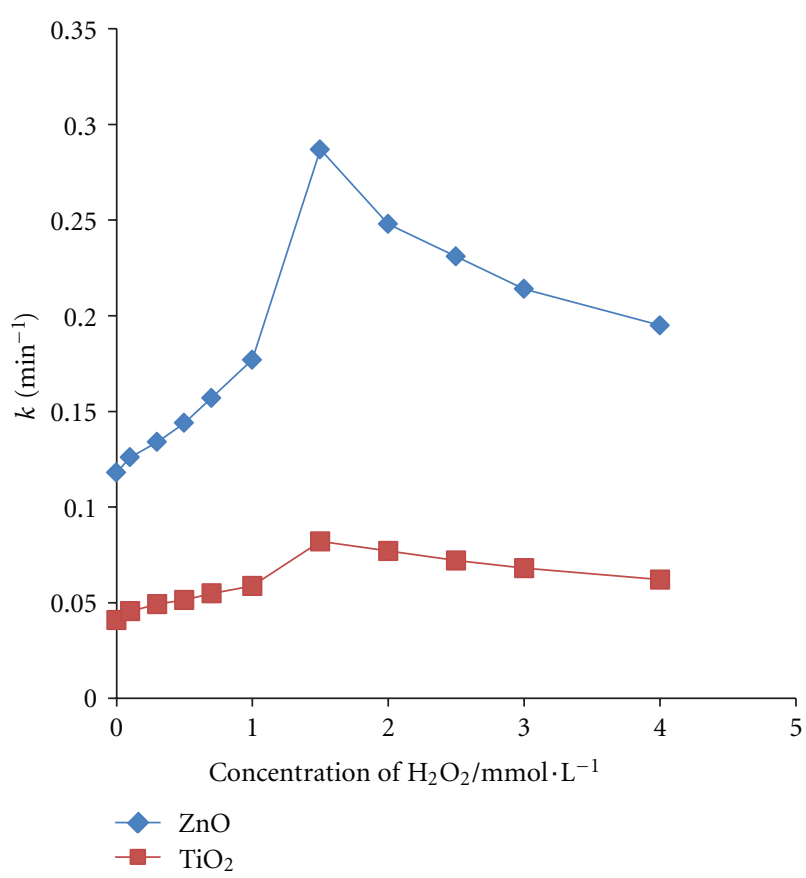

Figure 9: Effect of addition of $\mathrm{H}_{2} \mathrm{O}_{2}$ on rate constant.

At high concentration of hydrogen peroxide $\mathrm{H}_{2} \mathrm{O}_{2}$ the photocatalytic processes decrease because of its hydroxyl radical scavenging effect, according to the following equations [54]:

$$
\begin{gathered}
\mathrm{H}_{2} \mathrm{O}_{2}+{ }^{\bullet} \mathrm{OH} \longrightarrow \mathrm{H}_{2} \mathrm{O}+\mathrm{HO}_{2}^{\bullet} \\
\mathrm{HO}_{2}^{\bullet}+{ }^{\bullet} \mathrm{OH} \longrightarrow \mathrm{H}_{2} \mathrm{O}+\mathrm{O}_{2}
\end{gathered}
$$

3.8. Type of Catalyst. The results in Figure 10 show the relationship between the photodecolorization of cobalamin with irradiation time in the existence of oxygen gas by using different types of $\mathrm{TiO}_{2}$, under the experimental conditions, initial cobalamin concentration of $40 \mathrm{ppm}$, solution $\mathrm{pH}$ equal to 7.8 , light intensity equal to $1.3 \mathrm{~mW} \cdot \mathrm{cm}^{-2}, \mathrm{TiO}_{2} \mathrm{con}-$ centration $175(\mathrm{mg} / 100 \mathrm{~mL})$, and the temperature equal to $298.15 \mathrm{~K}$. The results show that the activity of different types of catalyst used in this study was of the sequence:

$\mathrm{TiO}_{2}\left(\right.$ Degussa P25) $>\mathrm{TiO}_{2}($ Hombikat UV100) $>$

$\mathrm{TiO}_{2}$ (Millennium PC105) $>\mathrm{TiO}_{2}$ (Koronose 2073)

3.9. Mineralization of Cobalamin. The results in Figures 11, 12 , and 13 show the relationship between the TOC degradation \% with irradiation time and it is found that the TOC degradation \% increased with the increase of the irradiation time. These results indicate that the color photodegradation for cobalamin is faster than the decrease of total organic carbon (TOC). From these results it is found that the $\mathrm{ZnO}$

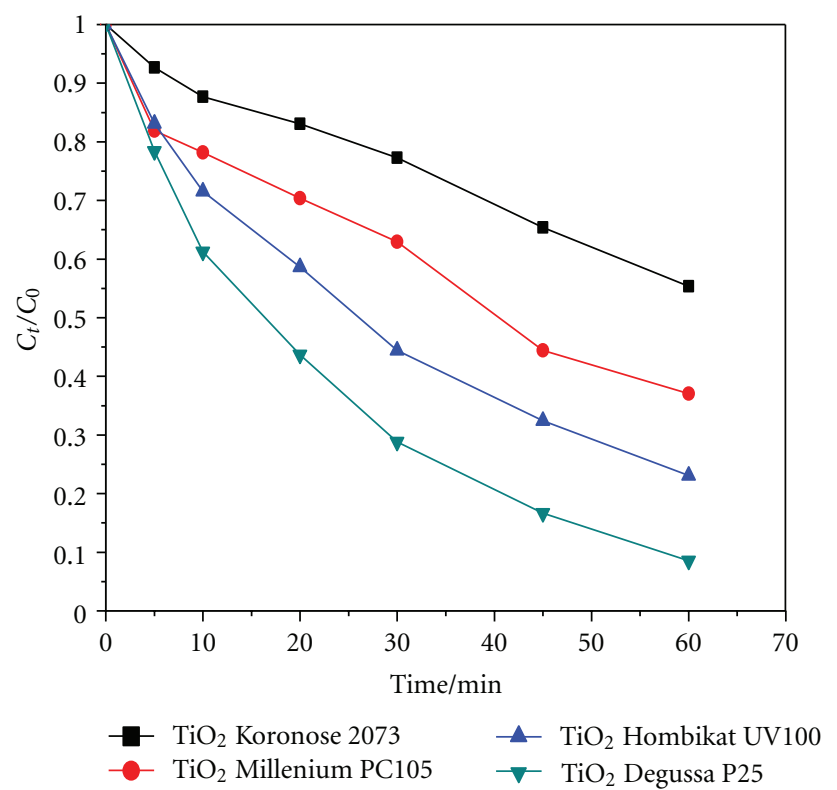

FIGURE 10: Photodecolorization of cobalamin by different types of $\mathrm{TiO}_{2}$.

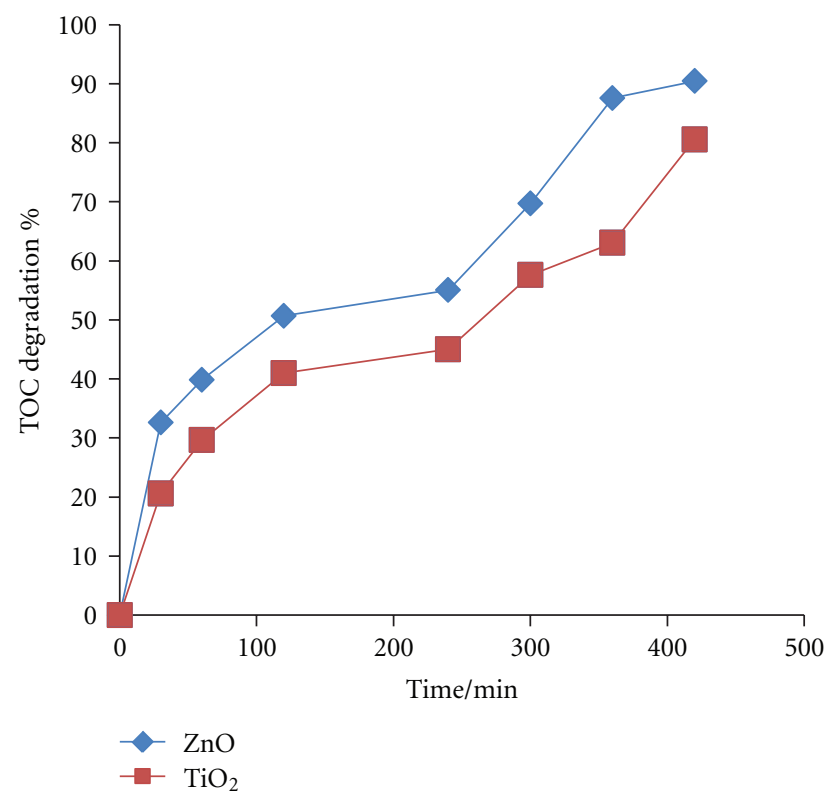

FIGURE 11: Mineralization of cobalamin.

is more active than the $\mathrm{TiO}_{2}$ (Degussa P25). The efficiency of these catalyst arrangements is as follows:

$$
\mathrm{ZnO}>\mathrm{TiO}_{2}(\text { Degussa P25) }
$$

\section{Conclusions}

Complete decolorization of cobalamin was achieved in less than thirty minutes. $\mathrm{PH}$ was changed at the end of reaction 


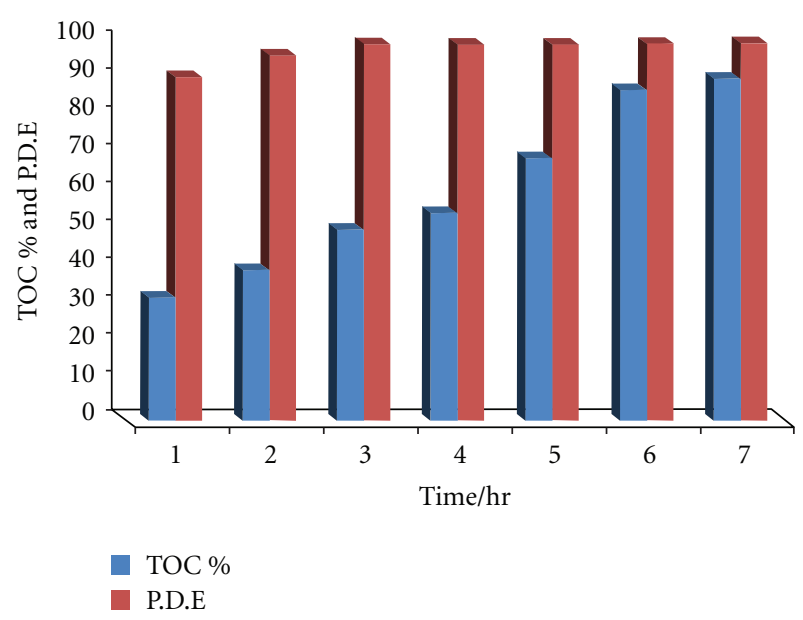

Figure 12: TOC degradation \% and P.D.E for cobalamin by $\mathrm{ZnO}$.

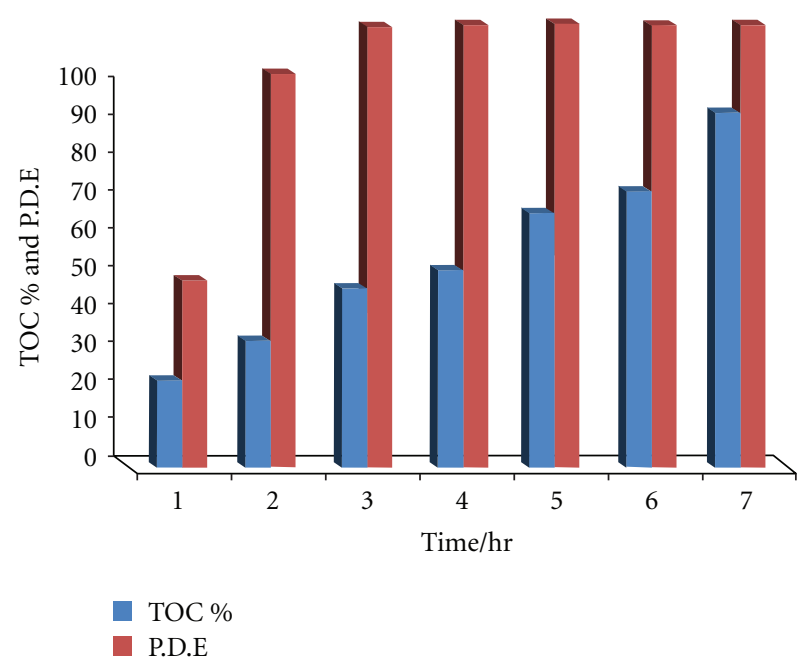

Figure 13: TOC degradation \% and P.D.E for cobalamin by $\mathrm{TiO}_{2}$ (Degussa P25).

towards 7 (neutral). The photocatalytic process can be expressed by both the pseudo-first-order reaction kinetics and the Langmuir-Hinshelwood kinetic model.

The controlled experiment indicates that the presence of UV light, oxygen, and catalyst was essential for the effective destruction of cobalamin. It is important to choose optimum degradation parameters to obtain a high photocatalytic decolorization rate.

The enhancement of decolorization efficiency of cobalamin increasing masses of catalysts is attributed to the increase of the availability of photocatalytic sites. Nevertheless, the decrease of catalytic activity often the plateau region is related to a shielding effect of excess partials and resulted in a reduced performance.

The photocatalytic decolorization of cobalamin using different types of catalysts like photocatalyst strongly depends on the amount of catalyst, cobalamin concentration, $\mathrm{pH}$ of solution, light intensity, type of current gas, and addition of $\mathrm{H}_{2} \mathrm{O}_{2}$.
The phenomenon of increasing the photodecolorization efficiency of cobalamin with decreasing the concentration of solution is due to the decrease of the concentration of $\mathrm{OH}^{-}$ adsorbed on catalyst surface. The increasing of cobalamin concentration increases the competitions between $\mathrm{OH}^{-}$and cobalamin to adsorb on active site of catalyst.

The photocatalytic decolorization efficiency of cobalamin increases with the increase of the $\mathrm{pH}$ of solution up to a maximum value and then decreases. This behavior could be explained on the basis of zero point charge (ZPC).

The decolorization of cobalamin increases with the increase of light intensity. Nevertheless, the increase of light intensity leads to the increase of the number of electron-hole pair and, hence, increases the decolorization efficiency of cobalamin.

The temperature is the factor that has the smallest effect on the photocatalytic decolorization of cobalamin. Photocatalytic decolorazation of cobalamin is faster than the decrease of total organic carbon (TOC).

\section{Acknowledgments}

The authors are gratefully acknowledging Prof. Dr. Detlef Bahnemann, "Photocatalysis and Nanotechnology" (Head), and Dr. Ralf Dillert, Institut fuer Technische Chemie, Leibniz Universitaet Hannover, Hannover, Germany, for providing the laboratory facilities during the work and also to Sachtleben Chemie GmbH, Duisburg/ Germany, for supplying Hommbikat samples.

\section{References}

[1] S. N. Frank and A. J. Bard, "Heterogeneous photocatalytic oxidation of cyanide ion in aqueous solutions at $\mathrm{TiO}_{2}$ powder," Journal of the American Chemical Society, vol. 99, no. 1, pp. 303-304, 1977.

[2] C. Belver, R. Bellod, A. Fuerte, and M. Fernández-García, "Nitrogen-containing $\mathrm{TiO}_{2}$ photocatalysts. Part 1. Synthesis and solid characterization," Applied Catalysis B, vol. 65, no. 34, pp. 301-308, 2006.

[3] F. H. Hussein, A. F. Halbus, H. A. K. Hassan, and W. A. K. Hussein, "Photocatalytic degradation of bismarck brown G using irradiated $\mathrm{ZnO}$ in aqueous solutions," E-Journal of Chemistry, vol. 7, no. 2, pp. 540-544, 2010.

[4] D. F. Ollis, E. Pelizzetti, and N. Serpone, Photocatalysis: Fundamentals and Applications, Wiley, New York, NY, USA, 1989.

[5] D. Robert and S. Malato, "Solar photocatalysis: a clean process for water detoxification," Science of the Total Environment, vol. 291, no. 1-3, pp. 85-97, 2002.

[6] A. Fujishima, T. N. Rao, and D. A. Tryk, "Titanium dioxide photocatalysis," Journal of Photochemistry and Photobiology C, vol. 1, no. 1, pp. 1-21, 2000.

[7] J. A. Byrne, P. A. Fernandez-Ibañez, P. S. M. Dunlop, D. M. A. Alrousan, and J. W. J. Hamilton, "Photocatalytic enhancement for solar disinfection of water: a review," International Journal of Photoenergy, vol. 2011, Article ID 798051, 12 pages, 2011.

[8] M. Zhou, J. Zhang, B. Cheng, and H. Yu, "Enhancement of visible-light photocatalytic activity of mesoporous $\mathrm{Au}-\mathrm{TiO}_{2}$ nanocomposites by surface plasmon resonance," International Journal of Photoenergy, vol. 2012, Article ID 532843, 10 pages, 2012. 
[9] G. Wang, L. Xu, J. Zhang, T. Yin, and D. Han, "Enhanced photocatalytic activity of $\mathrm{TiO}_{2}$ powders (P25) via calcination treatment," International Journal of Photoenergy, vol. 2012, Article ID 265760, 9 pages, 2012.

[10] H. Znad, M. H. Ang, and M. O. Tade, " $\mathrm{Ta} / \mathrm{TiO}{ }_{2}$-and $\mathrm{Nb} / \mathrm{TiO}_{2}$ mixed oxides as efficient solar photocatalysts: preparation, characterization, and photocatalytic activity," International Journal of Photoenergy, vol. 2012, Article ID 548158, 9 pages, 2012.

[11] X. Wu, Z. Huang, Y. Liu, and M. Fang, "Investigation on the photoelectrocatalytic activity of well-aligned $\mathrm{TiO}_{2}$ nanotube arrays," International Journal of Photoenergy, vol. 2012, Article ID 832516, 7 pages, 2012.

[12] X. Cheng, X. Yu, Z. Xing, and L. Yang, "Enhanced visible light photocatalytic activity of mesoporous anatase $\mathrm{TiO}_{2}$ codoped with nitrogen and chlorine," International Journal of Photoenergy, vol. 2012, Article ID 593245, 6 pages, 2012.

[13] C. H. Huang, Y. M. Lin, I. K. Wang, and C. M. Lu, "Photocatalytic activity and characterization of carbon-modified titania for visible-light-active photodegradation of nitrogen oxides," International Journal of Photoenergy, vol. 2012, Article ID 548647, 13 pages, 2012.

[14] Q. Wang, D. Gao, C. Gao et al., "Removal of a cationic dye by adsorption/photodegradation using electrospun PAN/OMMT composite nanofibrous membranes coated with $\mathrm{TiO}_{2}$," International Journal of Photoenergy, vol. 2012, Article ID 680419, 8 pages, 2012.

[15] J. Wang, Q. Cai, H. Li, Y. Cui, and H. Wang, "A reviewon $\mathrm{TiO}_{2}$ nanotube film photocatalysts prepared by liquid-phase deposition," International Journal of Photoenergy, vol. 2012, Article ID 702940, 11 pages, 2012.

[16] M. A. Behnajady, N. Modirshahla, M. Shokri, and B. Rad, "Enhancement of photocatalytic activity of $\mathrm{TiO}_{2}$ nanoparticles by Silver doping: photodeposition versus liquid impregnation methods," Global Nest Journal, vol. 10, no. 1, pp. 1-7, 2008.

[17] M. A. Behnajady, N. Modirshahla, and R. Hamzavi, "Kinetic study on photocatalytic degradation of C.I. Acid Yellow 23 by ZnO photocatalyst," Journal of Hazardous Materials, vol. 133, no. 1-3, pp. 226-232, 2006.

[18] M. Saquib and M. Muneer, " $\mathrm{TiO}_{2} /$ mediated photocatalytic degradation of a triphenylmethane dye (gentian violet), in aqueous suspensions," Dyes and Pigments, vol. 56, no. 1, pp. 37-49, 2003.

[19] P. Fernández-Ibáñez, J. Blanco, S. Malato, and F. J. de las Nieves, "Application of the colloidal stability of $\mathrm{TiOM}_{2}$ particles for recovery and reuse in solar photocatalysis," Water Research, vol. 37, no. 13, pp. 3180-3188, 2003.

[20] T. Ohno, "Preparation of visible light active S-doped $\mathrm{TiO}_{2}$ photocatalysts and their photocatalytic activities," Water Science and Technology, vol. 49, no. 4, pp. 159-163, 2004.

[21] A. N. Alkhateeb, F. H. Hussein, and K. A. Asker, "Photocatalytic decolonization of industrial wastewater under natural weathering conditions," Asian Journal of Chemistry, vol. 17, no. 2, pp. 1155-1159, 2005.

[22] F. H. Hussein and A. N. Alkhateeb, "Photo-oxidation of benzyl alcohol under natural weathering conditions," Desalination, vol. 209, no. 1-3, pp. 350-355, 2007.

[23] J. L. Sessler, E. Karnas, and E. Sedenberg, "Porphyrins and expanded porphyrins as receptors," Supramolecular Chemistry, vol. 1, pp. 1-29, 2012.

[24] Y. Bai, Photoelectron Spectroscopic Investigations of Porphyrins and Phthalocyanines on $\mathrm{Ag}(111)$ and $\mathrm{Au}(111)$ : Adsorption and
Reactivity, Friedrich-Alexander-Universität Erlangen-Nürnberg, 2010.

[25] L. Quaroni, J. Reglinski, and W. E. Smith, "Surface enhanced resonance raman scattering from cyanocobalamin and $5^{\prime}$ deoxyadenosylcobalamin," Journal of Raman Spectroscopy, vol. 26, pp. 1075-1076, 1995.

[26] G. Jaouen, Bioorganometallics: Biomolecules, Labeling, Medicine, Wiley-VCH, Weinheim, Germany, 2006.

[27] V. Herbert, "Vitamin B-12: plant sources, requirements, and assay," The American Journal of Clinical Nutrition, vol. 48, no. 3, pp. 852-858, 1988.

[28] I. Ahmad, W. Hussain, and A. A. Fareedi, "Photolysis of cyanocobalamin in aqueous solution," Journal of Pharmaceutical and Biomedical Analysis, vol. 10, no. 1, pp. 9-15, 1992.

[29] F. H. Hussein and T. A. Abassa, "Photocatalytic treatment of textile industrial wastewater," International Journal of Chemical Sciences, vol. 8, no. 3, pp. 1353-1364, 2010.

[30] M. A. Rahman and M. Muneer, "Photocatalysed degradation of two selected pesticide derivatives, dichlorvos and phosphamidon, in aqueous suspensions of titanium dioxide," Desalination, vol. 181, no. 1-3, pp. 161-172, 2005.

[31] Y. Abdollahi, A. H. Abdullah, Z. Zainal, and N. A. Yusof, "Photocatalytic degradation of p-Cresol by zinc oxide under UV irradiation," International Journal of Molecular Sciences, vol. 13, pp. 302-315, 2012.

[32] C. S. Turchi and D. F. Ollis, "Photocatalytic degradation of organic water contaminants: mechanisms involving hydroxyl radical attack," Journal of Catalysis, vol. 122, no. 1, pp. 178192, 1990.

[33] R. J. Davis, J. L. Gainer, G. O’Neal, and I. W. Wu, "Photocatalytic decolorization of wastewater dyes," Water Environment Research, vol. 66, no. 1, pp. 50-53, 1994.

[34] M. Abu Tariq, M. Faisal, and M. Muneer, "Semiconductormediated photocatalysed degradation of two selected azo dye derivatives, amaranth and bismarck brown in aqueous suspension," Journal of Hazardous Materials, vol. 127, no. 1-3, pp. 172-179, 2005.

[35] C. N. Chang, Y. S. Ma, G. C. Fang, A. C. Chao, M. C. Tsai, and H. F. Sung, "Decolorizing of lignin wastewater using the photochemical UV/ $\mathrm{TiO}_{2}$ process," Chemosphere, vol. 56, no. 10, pp. 1011-1017, 2004.

[36] A. Aguedach, S. Brosillon, J. Morvan, and E. K. Lhadi, "Photocatalytic degradation of azo-dyes reactive black 5 and reactive yellow 145 in water over a newly deposited titanium dioxide," Applied Catalysis B, vol. 57, no. 1, pp. 55-62, 2005.

[37] A. T. Toor, A. Verma, C. K. Jotshi, P. K. Bajpai, and V. Singh, "Photocatalytic degradation of direct yellow 12 dye using UV/ $\mathrm{TiO}_{2}$ in a shallow pond slurry reactor," Dyes and Pigments, vol. 68 , no. 1 , pp. 53-60, 2006.

[38] J. M. Herrmann, "Heterogeneous photocatalysis: fundamentals and applications to the removal of various types of aqueous pollutants," Catalysis Today, vol. 53, no. 1, pp. 115-129, 1999.

[39] Y. Wang, "Solar photocatalytic degradation of eight commercial dyes in $\mathrm{TiO}_{2}$ suspension," Water Research, vol. 34, no. 3, pp. 990-994, 2000.

[40] Y. C. Chung and C. Y. Chen, "Degradation of azo dye reactive violet 5 by $\mathrm{TiO}_{2}$ photocatalysis," Environmental Chemistry Letters, vol. 7, no. 4, pp. 347-352, 2009.

[41] E. Evgenidou, K. Fytianos, and I. Poulios, "Photocatalytic oxidation of dimethoate in aqueous solutions," Journal of Photochemistry and Photobiology A, vol. 175, no. 1, pp. 29-38, 2005. 
[42] Z. He, S. Song, H. Zhou, H. Ying, and J. Chen, "C.I. reactive black 5 decolorization by combined sonolysis and ozonation," Ultrasonics Sonochemistry, vol. 14, no. 3, pp. 298-304, 2007.

[43] L. B. Reutergådh and M. Iangphasuk, "Photocatalytic decolourization of reactive azo dye: a comparison between $\mathrm{TiO}_{2}$ and CdS photocatalysis," Chemosphere, vol. 35, no. 3, pp. 585-596, 1997.

[44] M. Kositzi, I. Poulios, K. Samara, E. Tsatsaroni, and E. Darakas, "Photocatalytic oxidation of cibacron yellow LS-R," Journal of Hazardous Materials, vol. 146, no. 3, pp. 680-685, 2007.

[45] N. Daneshvar, M. Rabbani, N. Modirshahla, and M. A. Behnajady, "Kinetic modeling of photocatalytic degradation of Acid Red 27 in $\mathrm{UV} / \mathrm{TiO}_{2}$ process," Journal of Photochemistry and Photobiology A, vol. 168, no. 1-2, pp. 39-45, 2004.

[46] K. Byrappa, A. K. Subramani, S. Ananda, K. M. Lokanatha Rai, R. Dinesh, and M. Yoshimura, "Photocatalytic degradation of rhodamine B dye using hydrothermally synthesized $\mathrm{ZnO}$," Bulletin of Materials Science, vol. 29, no. 5, pp. 433-438, 2006.

[47] M. Tokumura, H. Tawfeek Znad, and Y. Kawase, "Modeling of an external light irradiation slurry photoreactor: UV light or sunlight-photoassisted Fenton discoloration of azo-dye Orange II with natural mineral tourmaline powder," Chemical Engineering Science, vol. 61, no. 19, pp. 6361-6371, 2006.

[48] I. K. Konstantinou and T. A. Albanis, " $\mathrm{TiO}_{2}$-assisted photocatalytic degradation of azo dyes in aqueous solution: kinetic and mechanistic investigations: a review," Applied Catalysis B, vol. 49, no. 1, pp. 1-14, 2004.

[49] J. J. Vora, S. K. Chauhan, K. C. Parmar, S. B. Vasava, S. Sharma, and L. S. Bhutadiya, "Kinetic study of application of $\mathrm{ZnO}$ as a photocatalyst in heterogeneous medium," E-Journal of Chemistry, vol. 6, no. 2, pp. 531-536, 2009.

[50] V. Mirkhani, S. Tangestaninejad, M. Moghadam, M. H. Habibi, and A. Rostami-Vartooni, "Photocatalytic degradation of azo dyes catalyzed by $\mathrm{Ag}$ doped $\mathrm{TiO}_{2}$ photocatalyst," Journal of the Iranian Chemical Society, vol. 6, no. 3, pp. 578587, 2009.

[51] R. Zhang, C. Zhang, X. X. Cheng, L. Wang, Y. Wu, and Z. Guan, "Kinetics of decolorization of azo dye by bipolar pulsed barrier discharge in a three-phase discharge plasma reactor," Journal of Hazardous Materials, vol. 142, no. 1-2, pp. 105-110, 2007.

[52] M. I. Litter, "Heterogeneous photocatalysis: transition metal ions in photocatalytic systems," Applied Catalysis B, vol. 23, no. 2-3, pp. 89-114, 1999.

[53] M. A. Behnajady, N. Modirshahla, and M. Shokri, "Photodestruction of acid orange 7 (AO7) in aqueous solutions by UV/ $\mathrm{H}_{2} \mathrm{O}_{2}$ : influence of operational parameters," Chemosphere, vol. 55, no. 1, pp. 129-134, 2004.

[54] M. S. Mashkour, A. F. Al-Kaim, L. M. Ahmed, and F. H. Hussein, "Zinc oxide assisted photocatalytic decoloriztion of reactive red 2 dye," International Journal of Chemical Sciences, vol. 9, no. 3, pp. 969-979, 2011. 


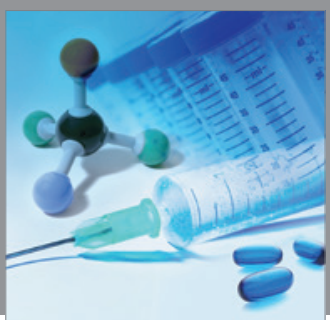

International Journal of

Medicinal Chemistry

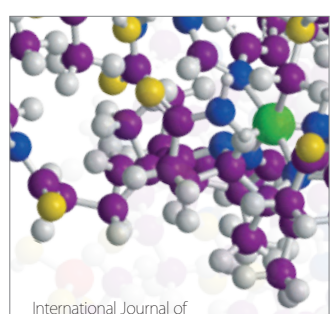

Carbohydrate Chemistry

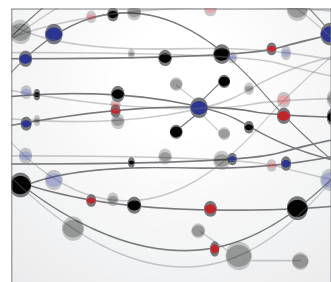

The Scientific World Journal
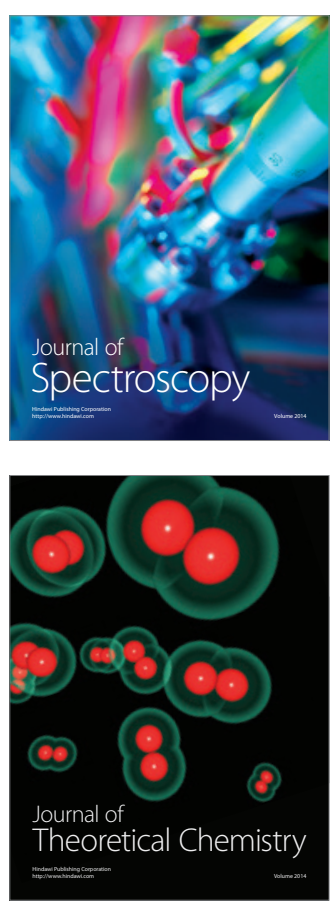
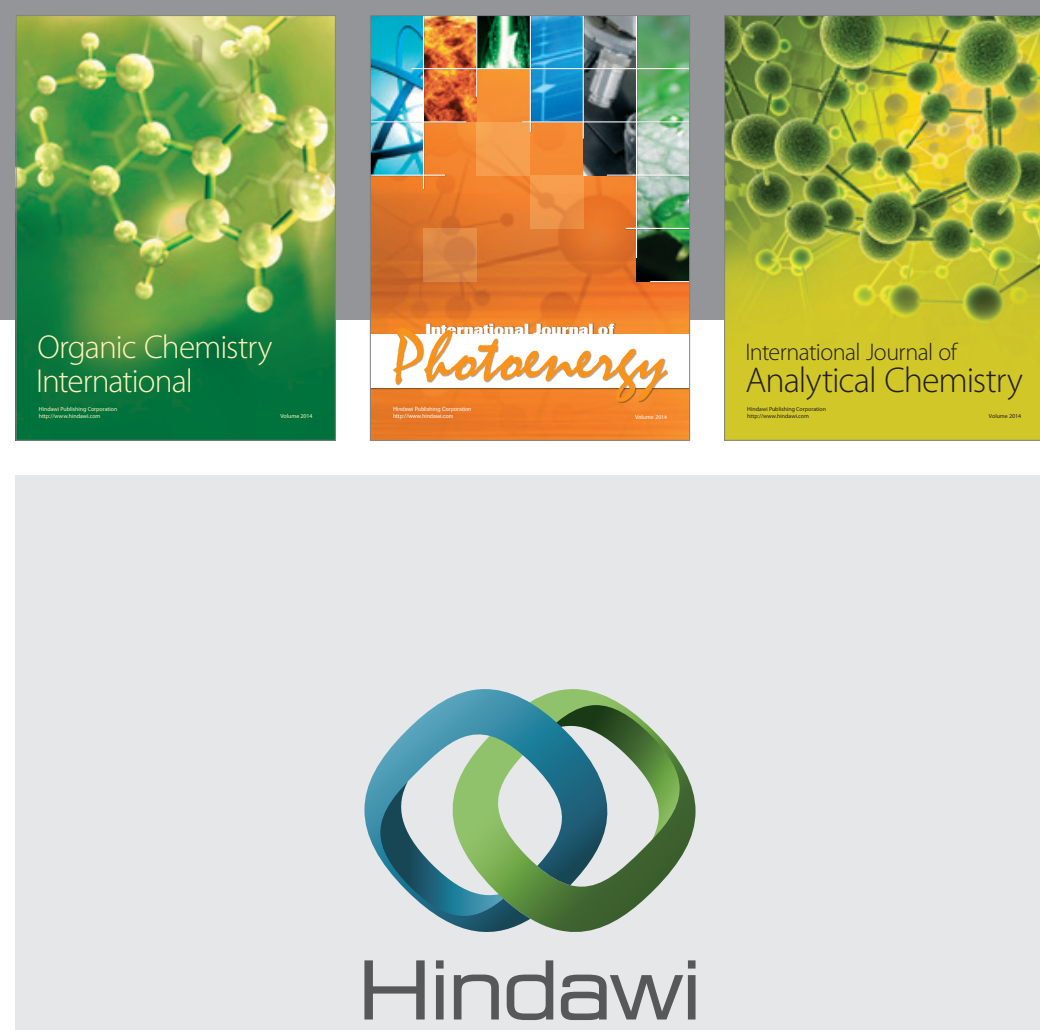

Submit your manuscripts at

http://www.hindawi.com
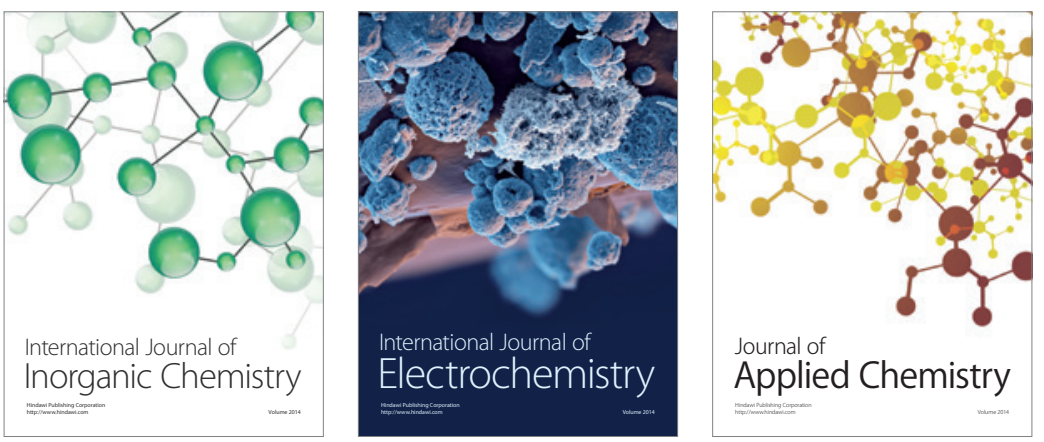

Journal of

Applied Chemistry
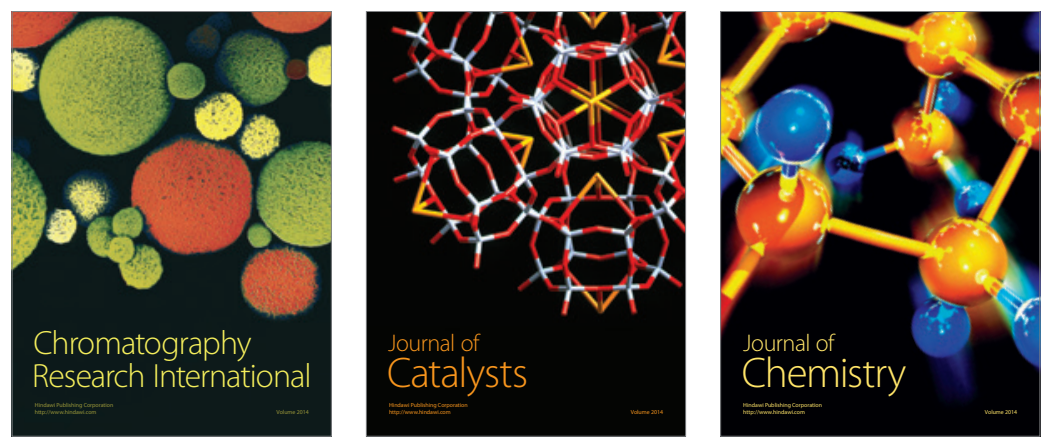
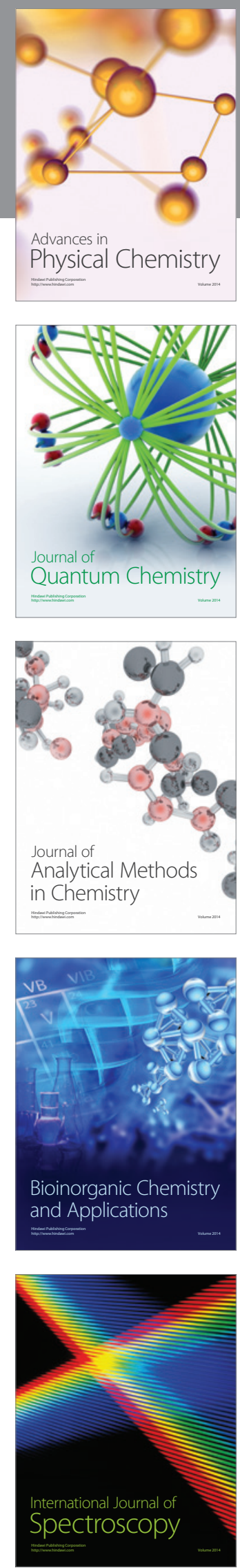